\title{
Keratinocyte-specific ablation of protease-activated receptor-2 prevents gingival inflammation and bone loss in a mouse model of periodontal disease
}

Nidhish Francis $^{1 *}$, Babatunde A. Ayodele ${ }^{1}$, Neil M. O’Brien-Simpson ${ }^{2}$, Walter Birchmeier ${ }^{3}$, Robert N. Pike ${ }^{4}$, Charles, N. Pagel ${ }^{1 \#}$, Eleanor J. Mackie ${ }^{1 \#}$

${ }^{1}$ Department of Veterinary Biosciences, Melbourne Veterinary School, University of Melbourne, Parkville, Victoria 3010, Australia.

${ }^{2}$ Melbourne Dental School, Bio21 Institute, University of Melbourne, Parkville, Victoria 3010, Australia

${ }^{3}$ Max-Delbrück-Center for Molecular Medicine, 13125 Berlin, Germany

${ }^{4}$ La Trobe Institute for Molecular Science, La Trobe University, Bundoora, Victoria 3086,

Australia

* Current address: School of Animal and Veterinary Sciences, Charles Sturt University, Wagga Wagga, NSW 2650, Australia

\# The last two authors made equal contributions to the manuscript

Corresponding author:

Prof. E.J. Mackie

Department of Veterinary Biosciences, Melbourne Veterinary School, Faculty of Veterinary and Agricultural Sciences, University of Melbourne, Parkville, Victoria 3010, Australia

Tel: +61383447360

This is the author manuscript accepted for publication and has undergone full peer review but has not been through the copyediting, typesetting, pagination and proofreading process, which may lead to differences between this version and the Version of Record. Please cite this article as doi: $10.1111 / \mathrm{cmi} .12891$

This article is protected by copyright. All rights reserved. 


\begin{abstract}
Chronic periodontitis is characterised by gingival inflammation and alveolar bone loss. A major aetiological agent is Porphyromonas gingivalis, which secretes proteases that activate protease-activated receptor-2 $\left(\mathrm{PAR}_{2}\right)$. $\mathrm{PAR}_{2}$ expressed on oral keratinocytes is activated by proteases released by $P$. gingivalis, inducing secretion of interleukin-6 (IL-6), and global knockout of $\mathrm{PAR}_{2}$ prevents bone loss and inflammation in a periodontal disease model in mice. To test the hypothesis that $\mathrm{PAR}_{2}$ expressed on gingival keratinocytes is required for periodontal disease pathology, keratinocyte-specific $\mathrm{PAR}_{2}$-null mice were generated using K14-Cre targeted deletion of the $\mathrm{PAR}_{2}$ gene $(F 2 r l 1)$. These mice were subjected to a model of periodontitis involving placement of a ligature around a tooth, combined with $P$. gingivalis infection ('Lig+Inf'). The intervention caused a significant $44 \%$ decrease in alveolar bone volume (assessed by micro-computed tomography) in wildtype (K14-Cre:F2rll ${ }^{w t / w t}$ ), but not littermate keratinocyte-specific $\mathrm{PAR}_{2}$-null (K14-Cre:F2rl1 $\left.{ }^{f l f l}\right)$ mice. Keratinocyte-specific ablation of $\mathrm{PAR}_{2}$ prevented the significant Lig+Inf-induced increase (2.8-fold) in the number of osteoclasts in alveolar bone and the significant up-regulation (2.4-4-fold) of the inflammatory markers IL-6, IL-1 $\beta$, interferon- $\gamma$, myeloperoxidase and CD11b in gingival tissue. These data suggest that $\mathrm{PAR}_{2}$ expressed on oral epithelial cells is a critical regulator
\end{abstract}


of periodontitis-induced bone loss and will help in designing novel therapies with which to treat the disease.

\section{INTRODUCTION}

The pathophysiology of chronic periodontitis involves establishment of a chronic inflammatory state in the gingiva, which leads to resorption of alveolar bone and ultimately tooth loss. The process is initiated by infection with bacteria including Porphyromonas gingivalis, which relies on production of a group of cysteine proteases known as the gingipains for its pathogenicity (Bostanci \& Belibasakis, 2012). Both the arginine-specific gingipain B (RgpB) and the lysine-specific gingipain (Kgp) activate the G-protein-coupled receptor, protease-activated receptor-2 (PAR 2 ; (Lourbakos et al., 1998, Liu et al., 2017). This receptor is expressed by many cells present in the normal periodontal tissues, including oral epithelial cells, gingival fibroblasts, osteoblasts and osteoclast precursors, as well as the neutrophils, macrophages, mast cells and lymphocytes that are present once inflammation is established (Lourbakos et al., 1998, Lourbakos et al., 2001, Abraham et al., 2000, Bar-Shavit et al., 2002, Belibasakis et al., 2010, D'Andrea et al., 2000, Smith et al., 2004).

Agonists of $\mathrm{PAR}_{2}$ can induce periodontal disease in rats when applied topically, and $\mathrm{PAR}_{2}$ is required for normal bone loss in a model of periodontal disease induced by $P$. gingivalis, as demonstrated in mice in which the $\mathrm{PAR}_{2}$ gene was deleted globally 
(Holzhausen et al., 2006, Holzhausen et al., 2005, Wong et al., 2010). While these studies highlighted the importance of $\mathrm{PAR}_{2}$ as a mediator of periodontal disease, they could not identify the critical $\mathrm{PAR}_{2}$-expressing cells, since $\mathrm{PAR}_{2}$ was absent from all cells in these mice. In global $\mathrm{PAR}_{2}$-null mice subjected to $P$. gingivalis-induced periodontal disease, $\mathrm{T}$ lymphocyte responses to the pathogen were defective, suggesting that these cells may require $\mathrm{PAR}_{2}$ for their contributions to the condition (Wong et al., 2010). We have recently generated a mouse line in which $\mathrm{PAR}_{2}$ was selectively ablated from $\mathrm{T}$ lymphocytes under the control of the Lck promoter (Francis et al., 2017). In these mice, T lymphocyte development was perturbed, suggesting that the aberrant $\mathrm{T}$ lymphocyte responses in global $\mathrm{PAR}_{2}$-null mice may result from the abnormal phenotype of these cells, rather than a requirement for $\mathrm{PAR}_{2}$ on mature T cells.

We have previously demonstrated that activation of $\mathrm{PAR}_{2}$ on oral epithelial cells by RgpB stimulates secretion of the pro-inflammatory cytokine interleukin-6 (IL-6; (Lourbakos et al., 2001). This observation led to the hypothesis that $\mathrm{PAR}_{2}$ on oral epithelial cells plays a critical role in the initiation of periodontal disease, since these are the first cells that come in contact with periodontal pathogens including $P$. gingivalis as they invade the gingiva. Based on this hypothesis, we have developed a model describing the role of $\mathrm{PAR}_{2}$ in the pathophysiology of periodontal disease. According to our model, IL-6, and possibly other factors released from oral epithelial cells in response to $\mathrm{PAR}_{2}$ activation, causes infiltration of the gingiva by inflammatory cells (neutrophils, macrophages, lymphocytes and mast cells). These cells also express $\mathrm{PAR}_{2}$ and secrete cytokines and/or $\mathrm{PAR}_{2}$-activating proteases, thus amplifying the inflammation. Consequently, the presence of cytokines (including IL-1, IL- 6, 
IL-17 and receptor activator of NF-אB ligand; RANKL) that stimulate differentiation and activity of the bone-resorbing osteoclasts ultimately leads to loss of alveolar bone (Kayal, 2013, Wong et al., 2010).

In order to test our hypothesis, we have generated a mouse line in which $\mathrm{PAR}_{2}$ is deleted from keratinocytes (including oral epithelial cells). Here we present the results of our studies investigating the responses of these mice to a model of periodontal disease.

\section{RESULTS}

\section{Characterisation of keratinocyte-specific $\mathbf{P A R} \mathbf{R}_{2}$-null mice}

Quantitative PCR analysis of exon 2 of F2rll in genomic DNA isolated from keratinocytes from the skin of newborn mice demonstrated that the abundance of the coding sequences of this gene in the keratinocytes of keratinocyte-specific $\mathrm{PAR}_{2}$-null (K14Cre:F2rll $\left.{ }^{f l f l}\right)$ mice was $94 \%$ lower than in those of their littermate wildtype (K14Cre:F2rl1 ${ }^{w t / w t}$ ) controls (Fig. 1A). Expression of F2rll transcripts was also significantly lower $(95 \%)$ in keratinocytes from $\mathrm{K} 14-\mathrm{Cre}: F 2 r l 1^{f l f l}$ mice as compared with those from K14Cre:F2rl1 ${ }^{w t / w t}$ mice (Fig. 1A).

Intracellular calcium mobilisation assays demonstrated that while treatment of keratinocytes from K14-Cre:F2rll flfl mice with the positive control, ATP, resulted in a normal response, these cells showed no response to either of the $\mathrm{PAR}_{2}$-activating peptides (2furoyl-LIGRLO-NH${ }_{2}$ and SLIGRL-NH 2 , at concentrations that yielded responses in $\mathrm{K} 14$ Cre:F2rl1 ${ }^{w t / w t}$ mice (Fig. 1B). Dermal fibroblasts from K14-Cre:F2rl1 ${ }^{f l f l}$ mice were, however, able to respond normally to the $\mathrm{PAR}_{2}$-activating peptides (Fig. 1B). 


\section{Combined ligature and infection model of periodontal disease in global PAR $\mathbf{R}_{2}$-null and control strains of mice}

Initial experiments were undertaken to confirm that the periodontal disease model combining application of a ligature to the second maxillary molar tooth with oral infection by

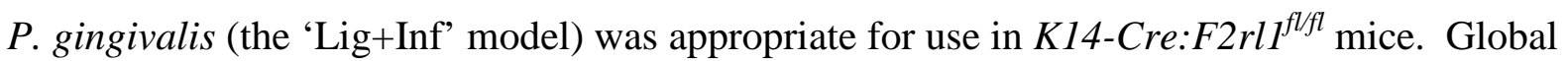
$\mathrm{PAR}_{2}$-null $\left(F 2 r l 1^{-/}\right)$, non-Cre $\mathrm{PAR}_{2}$ 'floxed' $\left(F 2 r l 1^{f l f l}\right)$ and wildtype $\left(F 2 r l l^{w t / w t}\right)$ mice were subjected to either Lig+Inf or sham treatment. Lig+Inf mice of all genotypes showed evidence of establishment of $P$. gingivalis infection, as demonstrated by both isolation of the bacteria from oral mucosa (detected by qPCR) and the presence of anti-P. gingivalis $\operatorname{IgG}$ in serum at the end of the experiment (Fig. 2A).

The alveolar BV/TV, as assessed by microCT, was significantly reduced by Lig+Inf in both the $F 2 r l l^{w t / w t}$ and $F 2 r l l^{f l f l}$ genotypes, whereas no significant change was observed in $\mathrm{F} \mathrm{rll}^{-/}$, mice (Fig. 2B). In agreement with this observation, osteoclast numbers in alveolar bone were increased by Lig+Inf in both the $F 2 r l 1^{\text {wt/wt }}$ and $F 2 r l 1^{f l f l}$ genotypes, whereas no significant change was observed in $F 2 r l 1^{-/}$, mice (Fig. 2C). The number of mast cells in the periodontal soft tissues was also significantly elevated in response to Lig+Inf in $F 2 r l 1^{w t / w t}$ and $F 2 r l l^{f l f l}$ mice, but not in $F 2 r l 1^{-/}$mice (Fig. 2D). In comparisons between mice of different genotypes in the Lig+Inf treatment group, the values for BV/TV were significantly higher in $F 2 r l 1^{-/}$mice than in both the $F 2 r l 1^{w t / w t}$ and $F 2 r l l^{f l f l}$ genotypes, and mast cell numbers were significantly lower in $F 2 r l 1^{-/-}$than in $F 2 r l l^{w t / w t}$ mice.

Expression of a number of inflammation-associated genes was analysed by qPCR in periodontal soft tissues collected at the end of the experiment. Expression of genes encoding 
IL-1 $\beta$ (Illb), IL-6 (Il6), interferon- $\gamma$ (Ifng), myeloperoxidase (Mpo), inducible nitric oxide synthase (Nos2) and CD11b (Cd11b) was upregulated by Lig+Inf treatment in mice of the two $\mathrm{PAR}_{2}$-expressing genotypes $\left(F 2 r l 1^{w t / w t}\right.$ and $\left.F 2 r l 1^{f l f l}\right)$, but not in $F 2 r l 1^{-/}$mice (Fig. 3). Expression of the gene encoding transforming growth factor- $\beta 1$ was up-regulated in all three genotypes, and expression of those encoding macrophage inflammatory protein-2 $(\mathrm{Cxcl})$ and tumour necrosis factor- $\alpha$ was not affected in any genotype (data not shown). In comparisons between mice of different genotypes in the Lig+Inf treatment group, the values for all of these genes were significantly lower in $F 2 r l 1^{-/}$mice than in both the $F 2 r l l^{w t / w t}$ and $F 2 r l I^{f l f l}$ genotypes, with the exception of that of $C d 1 \mathrm{lb}$, which was lower in $F 2 r l 1^{-/-}$than in $F 2 r l l^{f l f l}$ mice.

\section{Use of keratinocyte-specific $\mathbf{P A R}_{2}$-null mice in the periodontal disease model}

When K14-Cre:F2rl1 ${ }^{w t / w t}$ and K14-Cre:F2rll flfl mice were subjected to the periodontal disease model, the Lig+Inf groups for both genotypes showed evidence of infection with $P$. gingivalis, through detection of both bacteria and antibodies to them (Fig. 4A).

Alveolar bone loss was induced by Lig+Inf in K14-Cre:F2rl1 $1^{w t / w t}$, but not K14Cre:F2rl1 ${ }^{f l f l}$ mice, as demonstrated by microCT assessment of BV/TV (Fig. 4B). The number of osteoclasts in alveolar bone was elevated in response to Lig+Inf in K14Cre:F2rl1 ${ }^{w t / w t}$, but not K14-Cre:F2rl1 ${ }^{f l f l}$, mice. An increase in the number of mast cells in the periodontal soft tissues in response to Lig+Inf was, however, observed in both K14Cre:F2rl1 $1^{w t / w t}$ and K14-Cre:F2rll flfl mice (Fig. 4D). While serum IL-6 was elevated by Lig+Inf in K14-Cre:F2rll $1^{w t / w t}$ mice, no increase was observed in K14-Cre:F2rll ${ }^{f l f l}$ mice (Fig. 
4E). In comparisons between mice of different genotypes in the Lig+Inf treatment group, the values for BV/TV were significantly higher in K14-Cre:F2rll $1^{f l f l}$ than in K14-Cre:F2rll ${ }^{w t / w t}$ mice, and serum IL-6 levels were significantly lower in K14-Cre:F2rl1 ${ }^{\text {flfll }}$ than in K14Cre:F2rll $1^{w t / w t}$ mice.

As observed for $F 2 r l l^{w t / w t}$ and $F 2 r l 1^{f l f l}$ mice, six inflammation-associated genes were

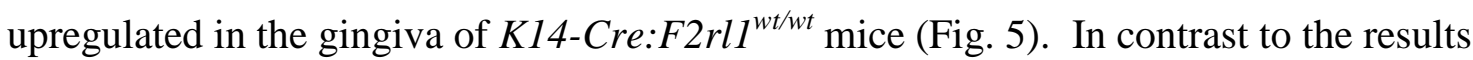

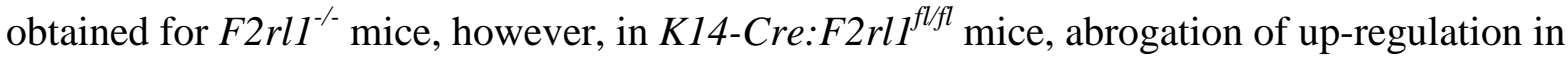
response to Lig+Inf was only observed for five of the six inflammation-associated genes (Fig. 5). The gene encoding iNOS was significantly up-regulated by Lig+Inf in K14-Cre:F2rllflfl mice. In comparisons between mice of different genotypes in the Lig+Inf treatment group, the values for all of these genes were significantly lower in K14-Cre:F2rll ${ }^{f l f l}$ than in K14Cre:F2rll $1^{w t / w t}$ mice, with the exception of that of Nos2, for which there was no significant difference between genotypes.

\section{DISCUSSION}

We have generated keratinocyte-specific $\mathrm{PAR}_{2}$-null mice in order to identify the role of $\mathrm{PAR}_{2}$ expressed by oral epithelial cells in periodontal disease. Our characterisation of the mice demonstrated that functional ablation of $\mathrm{PAR}_{2}$ was achieved specifically in keratinocytes, confirming that it was appropriate to use these mice to investigate our hypothesis.

In our previous study of periodontal disease in global $\mathrm{PAR}_{2}$-null mice, a model of periodontal disease dependent solely on oral infection with $P$. gingivalis was used, which 
requires 8 weeks from the time of initial infection until the mice are killed (Wong et al., 2010). In the current study, we chose to accelerate the pathology by combining the use of a ligature applied to the second maxillary molar teeth with oral $P$. gingivalis infection, allowing us to shorten the experimental period to 4 weeks, as described by (Lin et al., 2014). Initial experiments involved confirmation that this model was appropriate for the study of cell-type specific $\mathrm{PAR}_{2}$-null mice. This was achieved through the demonstration both that the alveolar bone loss and periodontal inflammation associated with periodontal disease were abrogated by global $\mathrm{PAR}_{2}$ knockout (i.e. in $F 2 r l 1^{-/-}$mice), and that they occurred normally in the $\mathrm{PAR}_{2}$ floxed $\left(F 2 r l l^{f l f l}\right)$ mice that we were planning to use to generate cell type-specific $\mathrm{PAR}_{2}$-null mouse lines.

The phenotype of K14-Cre:F2rll flffl mice subjected to the periodontal disease model mimicked that of $F 2 \mathrm{rll}^{-/}$mice in most of the assays undertaken. Importantly, the destructive bone loss, which eventually leads to tooth loss in human periodontal disease patients, was prevented by ablation of $\mathrm{PAR}_{2}$ expression in keratinocytes. Thus, it appears that activation of $\mathrm{PAR}_{2}$ on oral epithelial cells, most likely by gingipains released by $P$. gingivalis, is sufficient to initiate an inflammatory cascade ultimately leading to stimulation of osteoclast differentiation and activity. Evidence of induction of gingival inflammation by Lig+Inf in all the mouse strains with normal $\mathrm{PAR}_{2}$ expression $\left(F 2 r l 1^{w t / w t}, F 2 r l l^{f l f l}\right.$ and $\left.\mathrm{K} 14-\mathrm{Cre}: F 2 r l 1^{w t / w t}\right)$ was demonstrated by upregulation of the inflammatory cytokine genes $I l l b$, Il6 and Ifng, as well as Mpo, which is primarily expressed by neutrophils, and Nos 2 and $C d 11 b$, both of which are expressed by a variety of leukocytes, including neutrophils, macrophages, lymphocytes and mast cells, all of which are cells known to contribute to the pathology of 
periodontal disease (Malcolm et al., 2016, Kayal, 2013). Moreover, periodontal mast cell numbers were increased by Lig+Inf in all these mouse strains. In contrast, none of these parameters was increased by Lig+Inf in $\mathrm{F}_{2 \mathrm{rl}} \mathrm{I}^{--}$mice and none except Nos 2 expression and mast cell numbers was increased in $\mathrm{K} 14-\mathrm{Cre}: F 2 r l 1^{f l f l}$ mice.

Thus, it appears that while deletion of $\mathrm{PAR}_{2}$ on keratinocytes is sufficient to prevent most aspects of the inflammation observed in periodontal disease, it has no impact on gingival mast cell infiltration or Nos 2 expression, indicating that these two parameters require $\mathrm{PAR}_{2}$ expression by another cell type. We previously described the lack of mast cell infiltration into the periodontal tissues of $\mathrm{F}_{2} \mathrm{rl} 1^{-/}$mice infected orally with $P$. gingivalis, and on the basis of the observations proposed that $\mathrm{PAR}_{2}$ expressed by mast cells is required for their infiltration (Wong et al., 2010). Thus, the $\mathrm{PAR}_{2}$-expressing cells that allow for mast cell infiltration in keratinocyte-specific, but not global $\mathrm{PAR}_{2}$-null, mice may be the mast cells (or their precursors) themselves. However, it is also worth considering the identity of the protease(s) available for activation of $\mathrm{PAR}_{2}$ in the gingiva of keratinocyte-specific $\mathrm{PAR}_{2}$-null mice. We previously proposed that following initiation of the inflammatory response by gingipains activating $\mathrm{PAR}_{2}$ on gingival epithelial cells, the response is amplified by $\mathrm{PAR}_{2}{ }^{-}$ activating proteases secreted by the invading inflammatory cells, which in turn activate $\mathrm{PAR}_{2}$ on the inflammatory cells in an autocrine and/or paracrine manner (Wong et al., 2010). Such proteases include granzyme A (from lymphocytes), neutrophil elastase and mast cell tryptase (Adams et al., 2011, Ramachandran et al., 2011). However, in the absence of the normal inflammatory response in $\mathrm{K} 14-\mathrm{Cre}: \mathrm{F} 2 \mathrm{rl} 1^{f l f l}$ mice, these sources of host proteases are most likely not available prior to mast cell infiltration. The $P$. gingivalis-derived gingipains are 
present (at the gingival surface, at least), and it is likely that their activation of $\mathrm{PAR}_{2}$ on another normal gingival cell population such as fibroblasts leads to release of a chemoattractant for mast cells. For example, hepatocyte growth factor (HGF), secretion of which by gingival fibroblasts is stimulated in a $\mathrm{PAR}_{2}-$ dependent manner by gingipains, stimulates migration of mouse bone marrow-derived mast cells in vitro (Uehara et al., 2005, Fehlner-Gardiner et al., 1999); this may be the mechanism by which mast cells are attracted to the gingiva of mice lacking $\mathrm{PAR}_{2}$ in their oral epithelium.

Activation of $\mathrm{PAR}_{2}$ on mast cells leads to the release of inflammatory mediators, and we have proposed that this effect may contribute to periodontal disease pathology (Wong et al., 2010, Alshurafa et al., 2004, Carvalho et al., 2010, Moormann et al., 2006). More recently, a study in mast cell-deficient mice demonstrated that these cells are required for $P$. gingivalis-induced alveolar bone loss (Malcolm et al., 2016). The results of the current study indicate, however, that the presence of $\mathrm{PAR}_{2}$-expressing mast cells is not sufficient to cause alveolar bone loss in the absence of other important contributors to periodontal inflammation. It seems likely that what is missing in keratinocyte-specific $\mathrm{PAR}_{2}$-null mice exposed to Lig+Inf treatment is other inflammatory cells, which when available may act as mediators of mast cell-induced bone loss.

Up-regulation of Nos $2 / N O S 2$ in periodontal tissues in association with periodontal disease has been described in both animal models and human patients (Lohinai et al., 1998, Lappin et al., 2000). As noted above, Nos 2 is expressed by a variety of leukocytes. Due to the small amount of available material from each mouse, it was not possible in the current study to undertake immunohistochemical analysis of all of these cell types, but the fact that 
neither Mpo nor $C d 11 b$ was upregulated by Lig+Inf in $K 14-C r e: F 2 r l 1^{f l f l}$ mice suggests that there was minimal infiltration of the periodontal tissues by inflammatory cells other than mast cells in these mice. It appears likely, therefore, that mast cells were responsible for the Nos 2 expression. Inhibition of inducible nitric oxide synthase in a rat model of periodontal disease led to a decrease in alveolar bone loss (Herrera et al., 2011). However, in the current study, despite up-regulation of Nos2 in the gingiva of K14-Cre:F2rll $1^{f l f l}$ mice, there was no concomitant stimulation of alveolar bone loss, suggesting that Nos 2 expression is not sufficient to initiate alveolar bone loss in the absence of factors that are dependent on $\mathrm{PAR}_{2}$ expressed on keratinocytes. Inducible nitric oxide synthase is required for IL-1-induced osteoclastic bone resorption, but nitric oxide does not induce osteoclast differentiation in the absence of IL-1 (van't Hof et al., 2000); since Illb was up-regulated by Lig+Inf in the gingiva

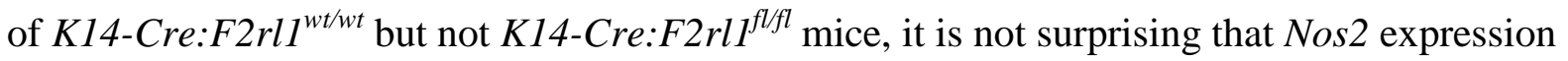
alone was insufficient to induce alveolar bone loss.

We have previously demonstrated that gingipains stimulate secretion of IL-6 by oral keratinocytes in vitro (Lourbakos et al., 2001), and according to our hypothesis, this IL-6 (and perhaps other inflammatory mediators) plays a critical role in attracting inflammatory cells to the site of $P$. gingivalis infection. Oral keratinocytes are probably not the only cells responsible for the IL-6 detected in the serum of Lig+Inf mice four weeks after initiation of periodontal disease; other cells present in inflamed periodontal tissues that are known to express IL-6 include neutrophils, lymphocytes and macrophages (Lundqvist et al., 1994, Grenier \& Grignon, 2006, Shpacovitch et al., 2004). It is likely that in mice with normal $\mathrm{PAR}_{2}$ expression, a combination of these cell types contributes to the elevated IL- 6 detected 
in serum. Circulating IL-6 levels in patients with periodontitis are higher than in healthy controls and decrease with treatments that lead to clinical improvement, and it has been suggested that this IL-6 may contribute to the association between periodontitis and other chronic conditions including cardiovascular disease and diabetes (D'Aiuto et al., 2004, Loos et al., 2000). Intriguingly, although the systemic and local chemokine/cytokine responses and bone loss were abrogated in Lig+Inf K14-Cre:F2rl fllfl mice in comparison to the Lig+Inf controls (K14-Cre:F2rl1 ${ }^{w t / w t}$ mice), the levels of $P$. gingivalis infection in the gingiva were equivalent. This suggests that a typical periodontal plaque biofilm has been established in all Lig+Inf animals. Thus, it appears that a key interaction is the activation of $\mathrm{PAR}_{2}$ on gingival keratinocytes by the gingipains released by $P$. gingivalis in the dental plaque biofilm. We could therefore speculate that bacterial burden alone is not enough to trigger disease pathology, however we cannot rule out the possibility that keratinocyte-specific $\mathrm{PAR}_{2}$ signalling in response to $P$. gingivalis proteases influences other components of the biofilm. Our observation that inactivation of $\mathrm{PAR}_{2}$ on keratinocytes alone can prevent this systemic manifestation of periodontal disease provides hope that targeted therapies can be developed that not only prevent bone (and therefore tooth) loss, but also the associated systemic conditions.

It may seem contradictory that Ifng up-regulation in gingival tissue is dependent on the presence of $\mathrm{PAR}_{2}$ on keratinocytes, since we previously demonstrated that $\mathrm{PAR}_{2}-$ activating proteases including RgpB do not stimulate secretion of interferon- $\gamma$ in cultured oral keratinocytes (Lourbakos et al., 2001). However, the gingival tissue used for quantitation of gene expression in the current study comprised connective tissue and any inflammatory 
infiltrate in addition to the epithelial component. Inflammatory cells, the presence of which is dependent on keratinocyte $\mathrm{PAR}_{2}$, are the most likely source of the up-regulated Ifng.

Gingipains are not the only enzymes from $P$. gingivalis required for its ability to induce alveolar bone loss. Peptidylarginine deiminase (PAD) is also required, as demonstrated by a study involving infection of mice with PAD-deficient $P$. gingivalis (Gully et al., 2014). This enzyme catalyses the citrullination of peptides, however serum from mice infected with control (PAD-expressing) $P$. gingivalis did not contain elevated levels of serum anti-citrullinated protein antibodies, thus the mechanism of induction of alveolar bone loss by $P$. gingivalis $\mathrm{PAD}$ is unclear. It is likely that both of these groups of $P$. gingivalis enzymes act in the same pathway, i.e. one downstream from the other, since inactivation of each one individually (deletion of PAD from $P$. gingivalis and deletion of $\mathrm{PAR}_{2}$ from the host) is able to prevent bone loss.

The results presented here provide evidence supporting our hypothesis that $\mathrm{PAR}_{2}$ on oral epithelial cells plays a critical role in the initiation of periodontal disease, and allow us to refine our model of the role of $\mathrm{PAR}_{2}$ in the pathophysiology of periodontal disease (Fig. 6). According to the model, $P$. gingivalis proteases activate $\mathrm{PAR}_{2}$ on gingival keratinocytes, resulting in secretion of IL-6 and possibly other inflammatory mediators, which in turn either directly or indirectly recruit inflammatory cells to the gingiva; these cells most likely include neutrophils, macrophages and lymphocytes, but not mast cells, which are able to accumulate in the absence of keratinocyte $\mathrm{PAR}_{2}$. The keratinocyte $\mathrm{PAR}_{2}$-dependent inflammatory cells secrete cytokines including IL-1 $\beta$, IFN- $\gamma$ and more IL-6. Moreover, T lymphocytes in inflamed periodontal tissues are known to secrete the osteoclastogenic factors IL-17 and 
RANKL (Kayal, 2013). These factors would collectively amplify the inflammatory response and stimulate osteoclast differentiation and bone resorption. While mast cell infiltration is not dependent on gingival keratinocyte $\mathrm{PAR}_{2}$ expression, it is dependent on global $\mathrm{PAR}_{2}$ expression, indicating the existence of a second $\mathrm{PAR}_{2}$-dependent pathway that contributes to gingival inflammation but is not sufficient to induce alveolar bone loss. In conclusion, as well as identifying a critical role for keratinocyte-specific $\mathrm{PAR}_{2}$ expression in bone loss in the context of periodontal disease, the results presented here demonstrate that although mast cells are necessary (Malcolm et al., 2016), they are not sufficient for bone loss in periodontal disease.

\section{EXPERIMENTAL PROCEDURES}

\section{Materials}

Reagents for cell culture were from GIBCO-ThermoFisher Scientific (Waltham, MA, USA) unless otherwise stated. Hyclone ${ }^{\mathrm{TM}}$ foetal bovine serum (FBS) was from ThermoFisher Scientific. Chemicals were from Sigma-Aldrich (St Louis, MO, USA) unless otherwise stated. Reagents for RNA extraction, reverse transcription and polymerase chain reaction (PCR) were from Promega (Madison, WI, USA). Oligonucleotide primers were custom synthesised by Geneworks (Thebarton, SA, Australia). Peptide agonists of PAR 2 were custom synthesised by Sigma-Aldrich. The P. gingivalis strain W50 (American Type Culture Collection, Manassas, VA, USA) was grown and prepared for mouse infection studies as described (O'Brien-Simpson et al., 2000b, O'Brien-Simpson et al., 2001). Heatkilled $P$. gingivalis strain W50 (HKW50) was prepared as described (Palm et al., 2013). 


\section{Animals}

Mice with global deletion of the gene encoding $\mathrm{PAR}_{2}\left(F 2 r l 1^{-/-}\right.$mice; (Lindner et al., 2000) were obtained from Dr S. R. Coughlin (University of California, San Francisco). The generation of mice with LoxP sites flanking exon 2 of the gene encoding $\mathrm{PAR}_{2}\left(F 2 r l{ }^{f l f l}\right.$ mice) has been described (Francis et al., 2017). These mice were crossed with mice expressing Cre-recombinase under the control of the keratin 14 (K14) promoter (K14Cre:F2rll ${ }^{w t / w t}$ mice; (Huelsken et al., 2001) to generate keratinocyte-specific $\mathrm{PAR}_{2}$-null $\left(\mathrm{K14-Cre}: \mathrm{F} \mathrm{rll}^{f l f l}\right)$ mice. Mouse colonies were maintained as heterozygous breeding stock, thus all experimental mice were littermates or the offspring of littermates.

The use of animals in this study was approved by the Gene Technology and Biosafety Committee of the University of Melbourne and the Animal Ethics Committee of the Faculty of Veterinary and Agricultural Sciences (AEC 1212655 and 1312922). Mice were housed in a controlled environment with free access to food and water, and all work was conducted in compliance with the Australian Code for the Care and Use of Animals for Scientific Purposes (2013) and the National Health and Medical Research Council's Guidelines for the Generation, Breeding, Care and Use of Genetically Modified and Cloned Animals for Scientific Purposes (2007).

\section{Cell culture}

Keratinocytes and dermal fibroblasts were isolated from the skin of newborn mice as described (Lichti et al., 2008). This method involved separation of the two cell types following floating of the skin overnight on trypsin $\left(0.25 \%[\mathrm{w} / \mathrm{v}] ; 4^{\circ} \mathrm{C}\right)$. Isolated 
keratinocytes were cultured in low calcium $(0.12 \mathrm{mM})$ Clonetics ${ }^{\mathrm{TM}}$ keratinocyte growth medium (KGM-2; Lonza, Basel, Switzerland) and dermal fibroblasts were cultured in Dulbecco's modified Eagle's medium containing FBS (10\% [v/v]), L-glutamine (300 $\mu \mathrm{g} / \mathrm{mL})$, gentamicin $(50 \mu \mathrm{g} / \mathrm{mL})$ and amphotericin B $(2.5 \mu \mathrm{g} / \mathrm{mL})$; cells were cultured in 96well plates $\left(3 \times 10^{4}\right.$ cells/well) for calcium mobilisation assays or in $35 \mathrm{~mm}$ dishes for extraction of RNA or genomic DNA.

\section{Polymerase chain reaction}

RNA was extracted from cultured cells and mouse tissues using Wizard SV RNA extraction columns (Promega, Madison, WI, USA). Genomic DNA was extracted from mouse ear clips (for genotyping of pups at weaning) using the HotSHOT genomic DNA extraction method (Truett et al., 2000) and from cultured cells using Wizard SV DNA purification columns (Promega) according to the manufacturer's instructions. First-strand cDNA was synthesised from purified RNA using the GoScript reverse transcription system (Promega).

Polymerase chain reaction was performed on template DNA in $20 \mu$ l total reaction volume containing forward and reverse oligonucleotide primers $(1 \mu \mathrm{M}$ each; Geneworks, Hindmarsh, SA, Australia; (Pagel et al., 2003). Primers for genotyping and quantitation of $\mathrm{PAR}_{2}$ exon 2 and GAPDH in genomic DNA (Francis et al., 2017), and $\mathrm{PAR}_{2}$ and cyclophilin A in RNA (Georgy et al., 2010) were as described; the other primers used were designed using Primer3 software (http://bioinfo.ut.ee/primer3/; Table 1), and their specificity confirmed by sequencing of transcripts. Thermal cycling was conducted over 35 cycles 
$\left(95^{\circ} \mathrm{C}\right.$ for $30 \mathrm{~s}, 56^{\circ} \mathrm{C}$ for $30 \mathrm{~s}$ and $72^{\circ} \mathrm{C}$ for $\left.30 \mathrm{~s}\right)$, prior to resolution of amplified products on agarose gels in the presence of SYBR Safe (Life Technologies, Grand Island, NY USA).

Quantitative PCR (qPCR) was performed on an MX3000p Real Time PCR Machine. PCR reactions containing $10 \mu \mathrm{l}$ ABI SYBR Green Supermix, $250 \mathrm{nM}$ each forward and reverse primer and $1 \mu 1 \mathrm{cDNA}$ or genomic DNA template, were incubated using the following cycle profile: $95^{\circ} \mathrm{C}$ for $10 \mathrm{~min}$, followed by 40 cycles consisting of $95^{\circ} \mathrm{C}$ for $30 \mathrm{~s}$, $60^{\circ} \mathrm{C}$ for $30 \mathrm{~s}$ and $72^{\circ} \mathrm{C}$ for $30 \mathrm{~s}$. Fluorescence readings were acquired at the end of each extension step in the FAM/SYBR channel of the machine. Following amplification, values for the cycle threshold $(\mathrm{Ct})$ for each primer pair and sample were exported to Microsoft Excel and analyzed using the Q-Gene tool (Simon, 2003). The Q-gene tool gives results as mean normalised expression (MNE; mean abundance normalised to a housekeeping gene), thus data for mRNA expression are presented as MNE (normalised to cyclophilin A) and data for $\mathrm{PAR}_{2}$ coding sequences in mouse cell genomic DNA are presented as mean abundance (normalised to GAPDH coding sequences).

\section{Calcium mobilisation}

Twenty-four hours after plating, cells were washed in assay buffer (Hanks' balanced salt solution containing $0.1 \%[\mathrm{w} / \mathrm{v}]$ bovine serum albumin) then incubated in assay buffer containing probenecid (2.5 mM), Fura-2 AM (1 $\mu \mathrm{M}$; Molecular Probes, Life Technologies) and pluronic acid $(0.01 \%$ [v/v] $)$ for $1 \mathrm{~h}$ at $37^{\circ} \mathrm{C}$. Following incubation, cells were washed twice with the assay buffer and incubated in assay buffer. The fluorescent emission at $510 \mathrm{~nm}$ after excitation at 340 and $380 \mathrm{~nm}$ was measured using a Flexstation 3 Multi-Mode microplate reader (Molecular Devices, Sunnyvale CA). Sixty seconds after commencement 
of the reading, $\mathrm{PAR}_{2}$ agonist (2-furoyl-LIGRLO-NH $2[10 \mu \mathrm{M}]$ or SLIGRL-NH $2[100 \mu \mathrm{M}]$ ), the positive control (ATP $[10 \mu \mathrm{M}]$ ) or the negative control (assay buffer) was injected into each well. The intracellular calcium concentration was expressed as the ratio of the emission at $510 \mathrm{~nm}$ following excitation at 340 and $380 \mathrm{~nm}$, respectively.

\section{Periodontal disease model}

A periodontal disease model involving a combination of application of a ligature to a tooth and infection with $P$. gingivalis was used. The experimental regimen was similar to that described by (Lin et al., 2014), with the exception that we administered more doses of $P$. gingivalis. Female mice (8-10 weeks old) of all genotypes were randomly assigned to either ligature and infection ('Lig+Inf') or sham groups. Mice were anaesthetized by intraperitoneal injection of ketamine $(100 \mathrm{mg} / \mathrm{kg}$ body weight; Troy Laboratories, Glendenning, NSW, Australia) and xylazine (10 mg/kg body weight; Troy Laboratories), then a ligature was tied around left and right second maxillary molar teeth as described (Abe $\&$ Hajishengallis, 2013). Commencing the next day, $P$. gingivalis strain W50 $\left(1 \times 10^{10}\right.$ bacterial cells in $2 \%$ [w/v] carboxymethyl cellulose [CMC]/dose) was administered topically to the gingiva every two days four times, followed by a 10-day break, then another four times two days apart. Mice assigned to the sham group received no ligature; they received $2 \%$ CMC without bacteria when the mice assigned to the Lig+Inf group received bacteria. Mice were killed 4 weeks after the placement of ligatures, then blood was collected by cardiac puncture for serum preparation, a sterile paper point was placed against the gingival margin of each maxilla for bacterial culture, and maxillae were excised and divided into halves. The gingiva surrounding the right half maxilla was removed and snap frozen in liquid nitrogen; 
the remaining bone was defleshed as described (Pathirana et al., 2007). The left half maxilla (with intact gingival tissue) was placed in $4 \%(\mathrm{w} / \mathrm{v})$ paraformaldehyde in phosphate-buffered saline (PBS) for preparation of cryosections. Submandibular lymph nodes were harvested for isolation of $\mathrm{T}$ cells.

Paper points were used for culture of recovered $P$. gingivalis for two days, as described (Baker et al., 2000). DNA was extracted from the bacterial samples for quantitation of bacteria using quantitative PCR as described (Pathirana et al., 2007). Standard curves using DNA isolated from pure cultures of $P$. gingivalis were generated for $P$. gingivalis $16 \mathrm{~S}$ rDNA and for a universally conserved region of 16S rDNA. Results are presented as $P$. gingivalis $16 \mathrm{~S}$ rDNA as a percentage of total bacterial $16 \mathrm{~S}$ rDNA in the same sample.

Serum was used to detect anti- $P$. gingivalis IgG by ELISA as described (O'BrienSimpson et al., 2000a) as well as IL-6 using an ELISA kit according to the manufacturer's instructions (R\&D Systems, Minneapolis, MN, USA).

\section{Micro-computed tomography}

To assess alveolar bone loss, the bone volume fraction (bone volume/tissue volume; $\mathrm{BV} / \mathrm{TV}$ ) of the alveolar bone on the buccal aspect of the three right maxillary molar teeth was measured from micro-computed tomography (microCT) images. Images of de-fleshed half maxillae were obtained using a Scanco microCT 50 at $70 \mathrm{kV}, 85 \mu \mathrm{A}, 18 \mu \mathrm{m}^{3}$ voxel and 0.5 mm aluminium filter (Scanco Medical, Brüttisellen, Switzerland). The 2D image sets were realigned such that the cemento-enamel junction (CEJ), the roof of furcation and the root apex of all molars are visible on the same sagittal image (using ImageJ version 1.5; 
https://imagej.nih.gov). The images were then reoriented in the dorsal plane, along the line connecting the CEJ of the first and third molar teeth, to draw a region of interest.

Measurements were undertaken by an operator blinded to the treatment groups (sham or Lig+Inf). For each maxilla, the distance from the CEJ to the alveolar bone crest (ABC) at the distal border of the second molar was estimated, and for each genotype the minimum and maximum CEJ-ABC distances were determined, representing no bone loss and maximum bone loss, respectively. The BV/TV of each sample was measured using all dorsal slices falling between the minimum and maximum CEJ-ABC distances. The mesial border of the region of interest was defined as a line drawn in each slice perpendicular to the mesial surface of the first molar, and the distal border was defined as a line adjacent to the distal surface of the third molar roots (see Supplementary Figure 1). Voxels attributable to bone within this region of interest in all slices were used to calculate BV/TV.

\section{Histology}

Following overnight incubation in fixative, left half maxillae were demineralised and processed for preparation of cryosections as described (Campbell et al., 2003). Sagittal sections $(8-10 \mu \mathrm{m})$ were cut using a cryostat (Leica CM 1900, Wetzlar, Germany). Sections were post-fixed in $4 \%(\mathrm{w} / \mathrm{v})$ paraformaldehyde in PBS for 5 minutes at room temperature prior to staining. Some sections were stained for the presence of the osteoclast-specific enzyme tartrate-resistant acid phosphatase (TRAP) by incubating with freshly prepared TRAP stain consisting of sodium tartrate $(30 \mathrm{mM})$, naphthol AS-MX phosphate $(0.1 \mathrm{mg} / \mathrm{ml})$, triton X-100 (0.1\% v/v) and fast red violet LB $(0.3 \mathrm{mg} / \mathrm{ml})$ in acetate buffer $(0.05 \mathrm{M})$ at room temperature for 10 minutes. After colour development, sections were rinsed with water, 
counterstained with Carazzi's haematoxylin and mounted in gelvatol. Some sections were stained with toluidine blue (1\% in $70 \%$ ethanol; 15 seconds), dehydrated and mounted in DPX. Sections were examined by brightfield microscopy (BX60; Olympus, Tokyo, Japan) and images were collected using a digital camera (Retiga 6000; QImaging, Surrey, BC, Canada). The area of alveolar bone extending from a vertical line touching the mesial surface of the first molar to a vertical line touching the distal surface of the third molar was measured using ImageJ. Osteoclasts were counted as TRAP-positive cells adherent to bone surfaces and containing more than two nuclei; results are presented as osteoclasts $/ \mathrm{mm}^{2}$ of bone. Mast cells, identified by their metachromatic granules in toluidine blue-stained sections, were counted in the gingival and periodontal connective tissue; results are presented as mast cells $/ \mathrm{mm}^{2}$ of soft tissue (measured using Image $\mathbf{J}$ ).

\section{Statistical analysis}

Data were analysed using GraphPad Prism software (version 5.01; La Jolla, CA, USA). Mean and standard error of the mean (SEM) are presented (as well as individual data points) in all graphs. Quantitative PCR data (where expressed as MNE) were analysed for significant differences by a pairwise fixed reallocation randomisation test, using REST-384 software (Pfaffl et al., 2002). Other data were analysed by unpaired Student's t-test for comparisons between two groups or ANOVA for multiple comparisons; Mann Whitney test or Kruskal-Wallis test with Dunn's multiple comparison test were used for data that were not normally distributed. P values $<0.05$ were considered significant.

\section{ACKNOWLEDGMENTS}


This work was supported by the National Health and Medical Research Council of Australia (project grant number 1044103). Nidhish Francis was supported by a Victoria India Doctoral Scholarship. The authors wish to thank Prof. Jan Potempa and Dr Malgorzata Benedyk (Jagiellonian University, Krakow, Poland) for training in application of ligatures to mouse molar teeth, and Prof. Nigel Bunnett and Dr Elva Zhao (Monash Institute of Pharmaceutical Sciences) for assistance with calcium mobilisation assays. No author has a conflict of interest. 
TABLE 1: Oligonucleotide primers

\begin{tabular}{|c|c|c|}
\hline Name & Forward (5'-3') & Reverse (5'-3') \\
\hline$C D 11 b$ & CATCAAGGGCAGCCAGATTG & GAGGCAAGGGACACACTGAC \\
\hline Cre & ATCTGGCATTTCTGGGGATTG & GGCAACACCATTTTTTCTGACC \\
\hline Ifng & CAGCAACAGCAAGGCGAAA & CTGGACCTGTGGGTTGTTGAC \\
\hline$\| 1 \mathrm{Ib}$ & GAAAGACGGCACACCCACC & AGACAAACCGTTTTTCCATCTTC \\
\hline 116 & GAGCCCACCAAGAACGATAG & TCAGTCCCAAGAAGGCAACT \\
\hline Mpo & CCGCCTGAACAATCAGTACC & ATTCTGGCGATTCAGTTTGG \\
\hline Nos2 & GAGGCCCAGGAGGAGAGAGATCCG & TCCATGCAGACAACCTTGGTGTTG \\
\hline $\begin{array}{l}P . \text { gingivalis-specific } \\
\text { 16S rDNA }\end{array}$ & TGCAACTTGCCTTACAGAGGG & TCAGTTCCCCTACCCATCGT \\
\hline Universal 16S rDNA & TCCTACGGGAGGCAGCAGT & GGACTACCAGGGTATCTAATCCTGTT \\
\hline
\end{tabular}

This article is protected by copyright. All rights reserved. 


\section{FIGURE LEGENDS}

\section{Figure 1: Characterisation of keratinocyte-specific $\mathbf{P A R} \mathbf{R}_{2}$-null mice}

A. Quantitative PCR analysis of $F 2 r l l$ exon 2 in genomic DNA and $F 2 r l l$ transcript in RNA

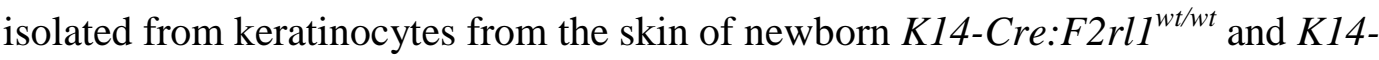

Cre:F2rll ${ }^{f l f l}$ mice; $* * * \mathrm{P}<0.001$. MNE - mean normalised expression. B. Calcium mobilisation assays conducted on keratinocytes and fibroblasts isolated from the skin of $\mathrm{K} 14$ Cre:F2rll ${ }^{w t / w t}$ and $K 14-C r e: F 2 r l 1^{f l f l}$ mice, treated with vehicle alone (negative control), ATP (positive control) and the $\mathrm{PAR}_{2}$ agonists, 2-furoyl-LIGRLO-NH $\mathrm{N}_{2}$ (2f-LI) and SLIGRL-NH 2 (SLI).

\section{Figure 2: The periodontal disease model in global $\mathbf{P A R}$-null and control strains of} mice: confirmation of $\boldsymbol{P}$. gingivalis infection and morphological changes Samples were obtained from wildtype $\left(F 2 r l l^{w t / w t}\right)$, non-Cre $\mathrm{PAR}_{2}$ 'floxed' $\left(F 2 r l 1^{f l f l}\right)$ and global PAR 2 -null $\left(F 2 r l 1^{--}\right)$mice subjected to sham and Lig+Inf treatments. A. Quantification of $P$. gingivalis cells in gingiva and $P$. gingivalis-specific IgG in serum; Mann-Whitney test. B. Upper panel - three-dimensional reconstructions of microCT images of half maxillae. Lower panel - BV/TV values; Student's t-test. C. Quantification of osteoclasts in cryosections of maxillae stained for the presence of TRAP. Upper panel - micrographs of sections from $F 2 r l l^{w t / w t}$ mice, showing osteoclasts (multinucleate TRAP-positive cells; arrows); $\mathrm{AB}$ - alveolar bone, $\mathrm{T}-$ tooth, $\mathrm{PL}$ - periodontal ligament; bar $=100 \mu \mathrm{m}$. Lower panel - osteoclast counts (TRAP-positive cells $/ \mathrm{mm}^{2}$ of alveolar bone) in the three genotypes; Student's t-test. D. Quantification of mast cells in cryosections of maxillae; Student's t-test. 
For comparisons between sham and Lig+Inf within genotypes: $* \mathrm{P}<0.05, * * \mathrm{P}<0.01, * * * \mathrm{P}$ $<0.001$, ns - no significant difference. For comparisons between $F 2 r l l^{w t / w t}$ and $F 2 r l 1^{-/}$ within treatments: \# P $<0.05$. For comparisons between $F 2 r l 1^{f l f l}$ and $F 2 r l 1^{-/}$within treatments: ${ }^{\wedge} \mathrm{P}<0.05$. Where there is no indication of a difference between genotypes, the difference was not significant.

\section{Figure 3: The periodontal disease model in global $\mathbf{P A R}_{2}$-null and control strains of} mice: gene expression in gingival tissue

Quantitative PCR analysis of expression of $I l 1 b$, Il6, Ifng, Mpo, Nos 2 and Cd1 $1 b$ in gingival tissue from wildtype $\left(F 2 r l 1^{w t / w t}\right)$, non-Cre $\mathrm{PAR}_{2}$ 'floxed' $\left(F 2 r l l^{f l f l}\right)$ and global $\mathrm{PAR}_{2}$-null $\left(F 2 \mathrm{rll}^{-}\right)$mice subjected to sham and Lig+Inf treatments. For comparisons between sham and Lig+Inf within genotypes: $* * \mathrm{P}<0.01, * * * \mathrm{P}<0.001$, ns - no significant difference. For comparisons between $F 2 r l 1^{w t / w t}$ and $F 2 r l 1^{-/}$within treatments: \#\# $\mathrm{P}<0.01$, \#\#\# $\mathrm{P}<0.001$. For comparisons between $F 2 r l 1^{f l f l l}$ and $F 2 r l 1^{-/}$within treatments: ${ }^{\wedge} \wedge \mathrm{P}<0.01,{ }^{\wedge \wedge \wedge} \mathrm{P}<0.001$. Where there is no indication of a difference between genotypes, the difference was not significant. MNE - mean normalised expression.

Figure 4: The periodontal disease model in keratinocyte-specific $\mathbf{P A R}_{2}$-null mice: confirmation of $\boldsymbol{P}$. gingivalis infection and morphological changes

Samples were obtained from K14-Cre:F2rll $I^{w t / w t}$ and K14-Cre:F2rll flffl mice subjected to sham and Lig+Inf treatments. A. Quantification of $P$. gingivalis cells in gingiva and $P$. gingivalis-specific IgG in serum; Kruskal-Wallis test with Dunn's multiple comparison test.

This article is protected by copyright. All rights reserved. 
B. Upper panel - three-dimensional reconstructions of microCT images of half maxillae. Lower panel - BV/TV values; two-way ANOVA with Sidak's multiple comparison test. C. Quantification of osteoclasts in cryosections of maxillae from $F 2 r l 1^{w t / w t}$ mice, stained for the presence of TRAP; two-way ANOVA with Sidak's multiple comparison test. D. Quantification of mast cells in cryosections of maxillae; two-way ANOVA with Sidak's multiple comparison test. E. Determination of IL-6 concentration in serum; two-way ANOVA with Sidak's multiple comparison test. For comparisons between sham and Lig+Inf within genotypes: $* \mathrm{P}<0.05,{ }^{*} \mathrm{P}<0.01, \mathrm{~ns}-$ no significant difference. For comparisons between K14-Cre:F2rll ${ }^{\text {wt/wt }}$ and K14-Cre:F2rl1 ${ }^{f l f l}$ within treatments: \# P $<0.05$. Where there is no indication of a difference between genotypes, the difference was not significant.

Figure 5: The periodontal disease model in keratinocyte-specific $P A R_{2}$-null mice: gene expression in gingival tissue

Quantitative PCR analysis of expression of $I l 1 b$, Il6, Ifng, Mpo, Nos 2 and Cd11b in gingival tissue from K14-Cre:F2rll ${ }^{w t / w t}$ and $K 14-C r e: F 2 r l 1^{f l f l}$ mice subjected to sham and Lig+Inf treatments. For comparisons between sham and Lig+Inf within genotypes: * $\mathrm{P}<0.05$, ** $\mathrm{P}<$ $0.01, * * * \mathrm{P}<0.001, \mathrm{~ns}-$ no significant difference. For comparisons between $\mathrm{K} 14$ Cre:F2rl1 $1^{w t / w t}$ and K14-Cre:F2rl1 ${ }^{f l f l}$ within treatments: \#\# $\mathrm{P}<0.01$, \#\#\# $\mathrm{P}<0.001$. Where there is no indication of a difference between genotypes, the difference was not significant. MNE - mean normalised expression. 
Figure 6: Schematic diagram illustrating our current understanding of the role of PAR in the pathophysiology of periodontal disease

When gingival epithelial cells are exposed to $P$. gingivalis-derived proteases, $\mathrm{PAR}_{2}$ on their surface is activated, leading to release of IL-6 and possibly other mediators, which in turn leads to infiltration of inflammatory cells, most likely macrophages and lymphocytes (shown here), as well as neutrophils. These cells in turn produce factors capable of stimulating osteoclast differentiation and activity and thus bone resorption. A second $\mathrm{PAR}_{2}$-mediated pro-inflammatory pathway appears to exist, which leads to mast cell infiltration; this may involve secretion of HGF by gingival fibroblasts in response to activation of $\mathrm{PAR}_{2}$ by $P$. gingivalis proteases. This pathway does not lead to bone resorption in the absence of $\mathrm{PAR}_{2}$ on gingival epithelium, but may contribute to IL-1 $\beta$-induced bone resorption through mast cell-derived nitric oxide (NO), when epithelial $\mathrm{PAR}_{2}$ is present.

\section{Supplementary Figure 1: The region of interest for determination of BV/TV in microCT images}

A microCT slice of a half maxilla oriented in the dorsal plane, with the region of interest for determination of BV/TV outlined in yellow. The mesial (left side of image) and distal (right side of image) limits of the region of interest are indicated with white lines. M1, M2, M3 the roots of molars 1-3.

This article is protected by copyright. All rights reserved. 


\section{REFERENCES}

Abe, T., and Hajishengallis, G. (2013) Optimization of the ligature-induced periodontitis model in mice. J Immunol Methods 394: 49-54.

Abraham, L.A., Chinni, C., Jenkins, A.L., Lourbakos, A., Ally, N., Pike, R.N., and Mackie, E.J. (2000) Expression of protease-activated receptor-2 by osteoblasts. Bone 26: 7-14.

Adams, M.N., Ramachandran, R., Yau, M.K., Suen, J.Y., Fairlie, D.P., Hollenberg, M.D., and Hooper, J.D. (2011) Structure, function and pathophysiology of protease activated receptors. Pharmacol Ther 130: 248-282.

Alshurafa, H.N., Stenton, G.R., Wallace, J.L., Hollenberg, M.D., Befus, A.D., and Vliagoftis, H. (2004) A protease activated receptor-2 (PAR-2) activating peptide, tc-LIGRLO$\mathrm{NH} 2$, induces protease release from mast cells: role in TNF degradation. BMC Pharmacol 4: 12.

Baker, P.J., Dixon, M., and Roopenian, D.C. (2000) Genetic control of susceptibility to Porphyromonas gingivalis-induced alveolar bone loss in mice. Infect Immun 68: 5864-5868.

Bar-Shavit, R., Maoz, M., Yongjun, Y., Groysman, M., Dekel, I., and Katzav, S. (2002) Signalling pathways induced by protease-activated receptors and integrins in T cells. Immunology 105: 35-46.

Belibasakis, G.N., Bostanci, N., and Reddi, D. (2010) Regulation of protease-activated receptor-2 expression in gingival fibroblasts and Jurkat $\mathrm{T}$ cells by Porphyromonas gingivalis. Cell Biol Int 34: 287-292.

Bostanci, N., and Belibasakis, G.N. (2012) Porphyromonas gingivalis: an invasive and evasive opportunistic oral pathogen. FEMS Microbiol Lett 333: 1-9.

Campbell, T.M., Wong, W.T., and Mackie, E.J. (2003) Establishment of a model of cortical bone repair in mice. Calcif Tissue Int 73: 49-55.

Carvalho, R.F., Nilsson, G., and Harvima, I.T. (2010) Increased mast cell expression of PAR2 in skin inflammatory diseases and release of IL-8 upon PAR-2 activation. Exp Dermatol 19: 117-122.

D'Aiuto, F., Parkar, M., Andreou, G., Suvan, J., Brett, P.M., Ready, D., and Tonetti, M.S. (2004) Periodontitis and systemic inflammation: control of the local infection is associated with a reduction in serum inflammatory markers. $J$ Dent Res 83: 156-160.

D'Andrea, M.R., Rogahn, C.J., and Andrade-Gordon, P. (2000) Localization of proteaseactivated receptors- 1 and -2 in human mast cells: indications for an amplified mast cell degranulation cascade. Biotech Histochem 75: 85-90.

Fehlner-Gardiner, C.C., Cao, H., Jackson-Boeters, L., Nakamura, T., Elliott, B.E., Uniyal, S., and Chan, B.M. (1999) Characterization of a functional relationship between hepatocyte growth factor and mouse bone marrow-derived mast cells. Differentiation 65: $27-42$.

Francis, N., Every, A.L., Ayodele, B.A., Pike, R.N., Mackie, E.J., and Pagel, C.N. (2017) A T cell-specific knockout reveals an important role for protease-activated receptor 2 in lymphocyte development. Int J Biochem Cell Biol 92: 95-103.

Georgy, S.R., Pagel, C.N., Wong, D.M., Sivagurunathan, S., Loh, L.H., Myers, D.E., Hollenberg, M.D., Pike, R.N., and Mackie, E.J. (2010) Proteinase-activated receptor-

This article is protected by copyright. All rights reserved. 
2 (PAR2) and mouse osteoblasts: regulation of cell function and lack of specificity of PAR2-activating peptides. Clin Exp Pharmacol Physiol 37: 328-336.

Grenier, D., and Grignon, L. (2006) Response of human macrophage-like cells to stimulation by Fusobacterium nucleatum ssp. nucleatum lipopolysaccharide. Oral Microbiol Immunol 21: 190-196.

Gully, N., Bright, R., Marino, V., Marchant, C., Cantley, M., Haynes, D., Butler, C., Dashper, S., Reynolds, E., and Bartold, M. (2014) Porphyromonas gingivalis peptidylarginine deiminase, a key contributor in the pathogenesis of experimental periodontal disease and experimental arthritis. PLoS One 9: e100838.

Herrera, B.S., Martins-Porto, R., Maia-Dantas, A., Campi, P., Spolidorio, L.C., Costa, S.K., Van Dyke, T.E., Gyurko, R., and Muscara, M.N. (2011) iNOS-derived nitric oxide stimulates osteoclast activity and alveolar bone loss in ligature-induced periodontitis in rats. J Periodontol 82: 1608-1615.

Holzhausen, M., Spolidorio, L.C., Ellen, R.P., Jobin, M.C., Steinhoff, M., Andrade-Gordon, P., and Vergnolle, N. (2006) Protease-activated receptor-2 activation: a major role in the pathogenesis of Porphyromonas gingivalis infection. Am J Pathol 168: 11891199.

Holzhausen, M., Spolidorio, L.C., and Vergnolle, N. (2005) Proteinase-activated receptor-2 (PAR2) agonist causes periodontitis in rats. J Dent Res 84: 154-159.

Huelsken, J., Vogel, R., Erdmann, B., Cotsarelis, G., and Birchmeier, W. (2001) beta-Catenin controls hair follicle morphogenesis and stem cell differentiation in the skin. Cell 105: 533-545.

Kayal, R.A. (2013) The role of osteoimmunology in periodontal disease. Biomed Res Int 2013: 639368.

Lappin, D.F., Kjeldsen, M., Sander, L., and Kinane, D.F. (2000) Inducible nitric oxide synthase expression in periodontitis. J Periodontal Res 35: 369-373.

Lichti, U., Anders, J., and Yuspa, S.H. (2008) Isolation and short-term culture of primary keratinocytes, hair follicle populations and dermal cells from newborn mice and keratinocytes from adult mice for in vitro analysis and for grafting to immunodeficient mice. Nat Protoc 3: 799-810.

Lin, J., Bi, L., Yu, X., Kawai, T., Taubman, M.A., Shen, B., and Han, X. (2014) Porphyromonas gingivalis exacerbates ligature-induced, RANKL-dependent alveolar bone resorption via differential regulation of Toll-like receptor 2 (TLR2) and TLR4. Infect Immun 82: 4127-4134.

Lindner, J.R., Kahn, M.L., Coughlin, S.R., Sambrano, G.R., Schauble, E., Bernstein, D., Foy, D., Hafezi-Moghadam, A., and Ley, K. (2000) Delayed onset of inflammation in protease-activated receptor-2-deficient mice. J Immunol 165: 6504-6510.

Liu, Y., Wu, Z., Nakanishi, Y., Ni, J., Hayashi, Y., Takayama, F., Zhou, Y., Kadawaki, T., and Nakanishi, H. (2017) Infection of microglia with Porphyromonas gingivalis promotes cell migration and an inflammatory response through the gingipainmediated activation of protease-activated receptor-2 in mice. Sci Rep 7: 11759.

Lohinai, Z., Benedek, P., Feher, E., Gyorfi, A., Rosivall, L., Fazekas, A., Salzman, A.L., and Szabo, C. (1998) Protective effects of mercaptoethylguanidine, a selective inhibitor of 
inducible nitric oxide synthase, in ligature-induced periodontitis in the rat. $\mathrm{Br} J$ Pharmacol 123: 353-360.

Loos, B.G., Craandijk, J., Hoek, F.J., Wertheim-van Dillen, P.M., and van der Velden, U. (2000) Elevation of systemic markers related to cardiovascular diseases in the peripheral blood of periodontitis patients. J Periodontol 71: 1528-1534.

Lourbakos, A., Chinni, C., Thompson, P., Potempa, J., Travis, J., Mackie, E.J., and Pike, R.N. (1998) Cleavage and activation of proteinase-activated receptor-2 on human neutrophils by gingipain-R from Porphyromonas gingivalis. FEBS Lett 435: 45-48.

Lourbakos, A., Potempa, J., Travis, J., D'Andrea, M.R., Andrade-Gordon, P., Santulli, R., Mackie, E.J., and Pike, R.N. (2001) Arginine-specific protease from Porphyromonas gingivalis activates protease-activated receptors on human oral epithelial cells and induces interleukin-6 secretion. Infect Immun 69: 5121-5130.

Lundqvist, C., Baranov, V., Teglund, S., Hammarstrom, S., and Hammarstrom, M.L. (1994) Cytokine profile and ultrastructure of intraepithelial gamma delta $\mathrm{T}$ cells in chronically inflamed human gingiva suggest a cytotoxic effector function. J Immunol 153: 2302-2312.

Malcolm, J., Millington, O., Millhouse, E., Campbell, L., Adrados Planell, A., Butcher, J.P., Lawrence, C., Ross, K., Ramage, G., McInnes, I.B., and Culshaw, S. (2016) Mast Cells Contribute to Porphyromonas gingivalis-induced Bone Loss. J Dent Res 95 : 704-710.

Moormann, C., Artuc, M., Pohl, E., Varga, G., Buddenkotte, J., Vergnolle, N., Brehler, R., Henz, B.M., Schneider, S.W., Luger, T.A., and Steinhoff, M. (2006) Functional characterization and expression analysis of the proteinase-activated receptor-2 in human cutaneous mast cells. J Invest Dermatol 126: 746-755.

O'Brien-Simpson, N.M., Black, C.L., Bhogal, P.S., Cleal, S.M., Slakeski, N., Higgins, T.J., and Reynolds, E.C. (2000a) Serum immunoglobulin G (IgG) and IgG subclass responses to the RgpA-Kgp proteinase-adhesin complex of Porphyromonas gingivalis in adult periodontitis. Infect Immun 68: 2704-2712.

O'Brien-Simpson, N.M., Paolini, R.A., Hoffmann, B., Slakeski, N., Dashper, S.G., and Reynolds, E.C. (2001) Role of RgpA, RgpB, and Kgp proteinases in virulence of Porphyromonas gingivalis $\mathrm{W} 50$ in a murine lesion model. Infect Immun 69: 75277534.

O'Brien-Simpson, N.M., Paolini, R.A., and Reynolds, E.C. (2000b) RgpA-Kgp peptide-based immunogens provide protection against Porphyromonas gingivalis challenge in a murine lesion model. Infect Immun 68: 4055-4063.

Pagel, C.N., de Niese, M.R., Abraham, L.A., Chinni, C., Song, S.J., Pike, R.N., and Mackie, E.J. (2003) Inhibition of osteoblast apoptosis by thrombin. Bone 33: 733-743.

Palm, E., Khalaf, H., and Bengtsson, T. (2013) Porphyromonas gingivalis downregulates the immune response of fibroblasts. BMC Microbiol 13: 155.

Pathirana, R.D., O'Brien-Simpson, N.M., Brammar, G.C., Slakeski, N., and Reynolds, E.C. (2007) Kgp and RgpB, but not RgpA, are important for Porphyromonas gingivalis virulence in the murine periodontitis model. Infect Immun 75: 1436-1442. 
Pfaffl, M.W., Horgan, G.W., and Dempfle, L. (2002) Relative expression software tool (REST) for group-wise comparison and statistical analysis of relative expression results in real-time PCR. Nucleic Acids Res 30: e36.

Ramachandran, R., Mihara, K., Chung, H., Renaux, B., Lau, C.S., Muruve, D.A., DeFea, K.A., Bouvier, M., and Hollenberg, M.D. (2011) Neutrophil elastase acts as a biased agonist for proteinase-activated receptor-2 (PAR2). J Biol Chem 286: 24638-24648.

Shpacovitch, V.M., Varga, G., Strey, A., Gunzer, M., Mooren, F., Buddenkotte, J., Vergnolle, N., Sommerhoff, C.P., Grabbe, S., Gerke, V., Homey, B., Hollenberg, M., Luger, T.A., and Steinhoff, M. (2004) Agonists of proteinase-activated receptor-2 modulate human neutrophil cytokine secretion, expression of cell adhesion molecules, and migration within 3-D collagen lattices. J Leukoc Biol 76: 388-398.

Simon, P. (2003) Q-Gene: processing quantitative real-time RT-PCR data. Bioinformatics 19: 1439-1440.

Smith, R., Ransjo, M., Tatarczuch, L., Song, S.J., Pagel, C., Morrison, J.R., Pike, R.N., and Mackie, E.J. (2004) Activation of protease-activated receptor-2 leads to inhibition of osteoclast differentiation. J Bone Miner Res 19: 507-516.

Truett, G.E., Heeger, P., Mynatt, R.L., Truett, A.A., Walker, J.A., and Warman, M.L. (2000) Preparation of PCR-quality mouse genomic DNA with hot sodium hydroxide and tris (HotSHOT). Biotechniques 29: 52, 54.

Uehara, A., Muramoto, K., Imamura, T., Nakayama, K., Potempa, J., Travis, J., Sugawara, S., and Takada, H. (2005) Arginine-specific gingipains from Porphyromonas gingivalis stimulate production of hepatocyte growth factor (scatter factor) through protease-activated receptors in human gingival fibroblasts in culture. J Immunol 175: 6076-6084.

van't Hof, R.J., Armour, K.J., Smith, L.M., Armour, K.E., Wei, X.Q., Liew, F.Y., and Ralston, S.H. (2000) Requirement of the inducible nitric oxide synthase pathway for IL-1-induced osteoclastic bone resorption. Proc Natl Acad Sci U S A 97: 7993-7998.

Wong, D.M., Tam, V., Lam, R., Walsh, K.A., Tatarczuch, L., Pagel, C.N., Reynolds, E.C., O'Brien-Simpson, N.M., Mackie, E.J., and Pike, R.N. (2010) Protease-activated receptor 2 has pivotal roles in cellular mechanisms involved in experimental periodontitis. Infect Immun 78: 629-638. 

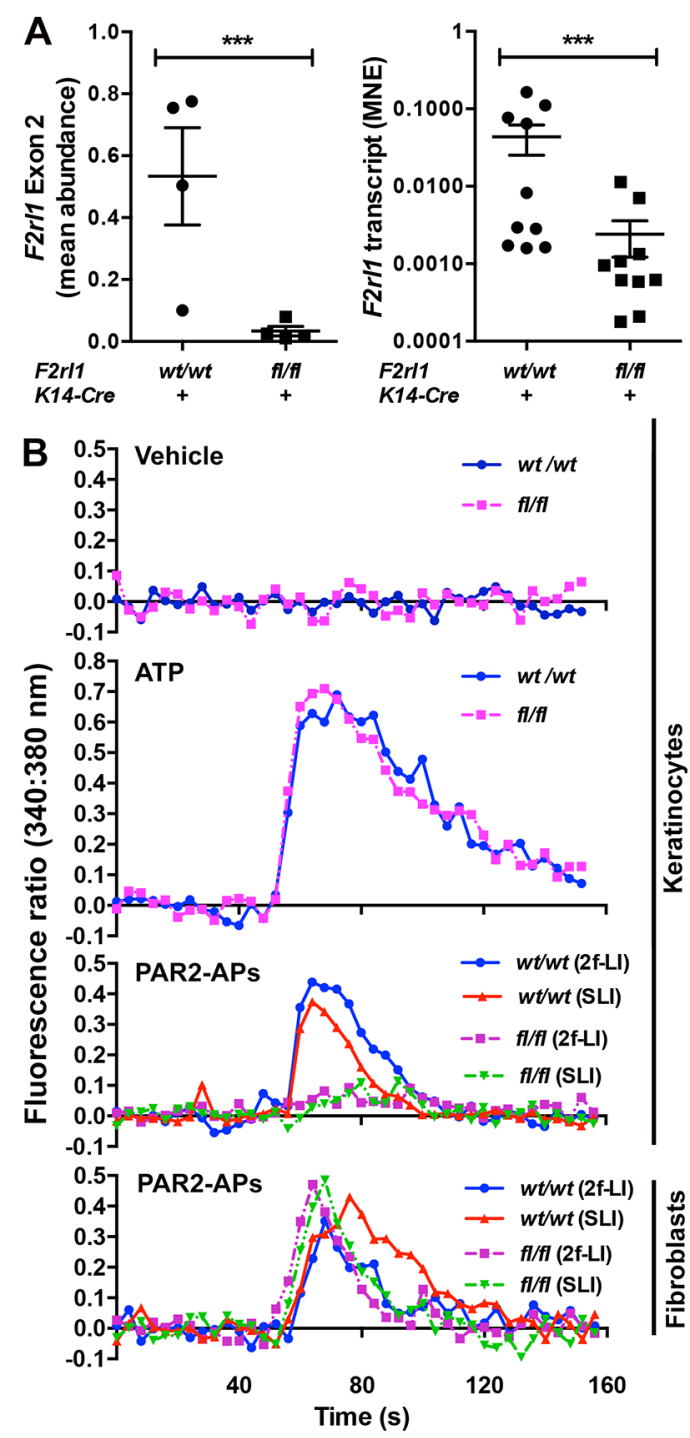

CMI_12891_F1.tif

This article is protected by copyright. All rights reserved. 

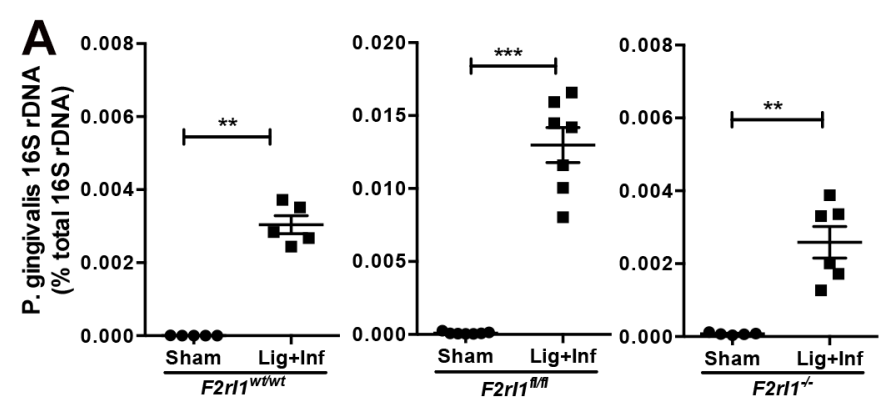

B

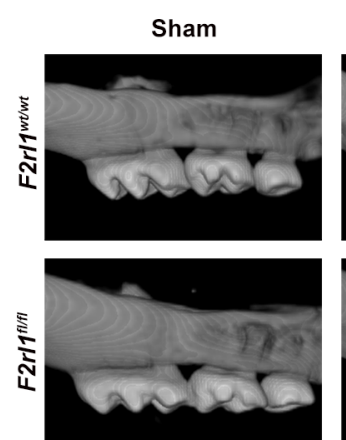

Lig+Inf
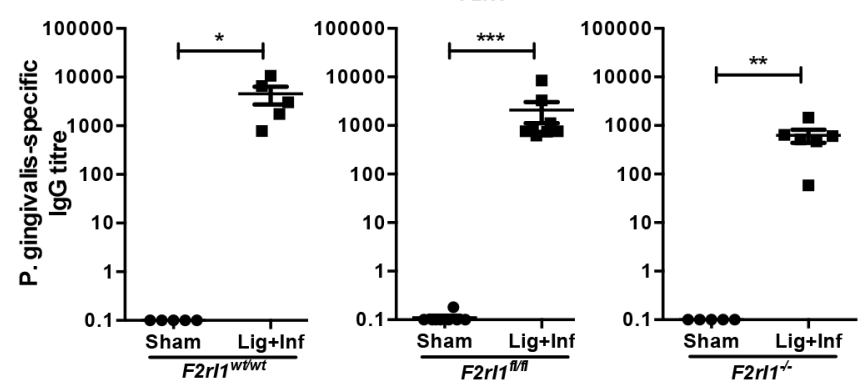

C
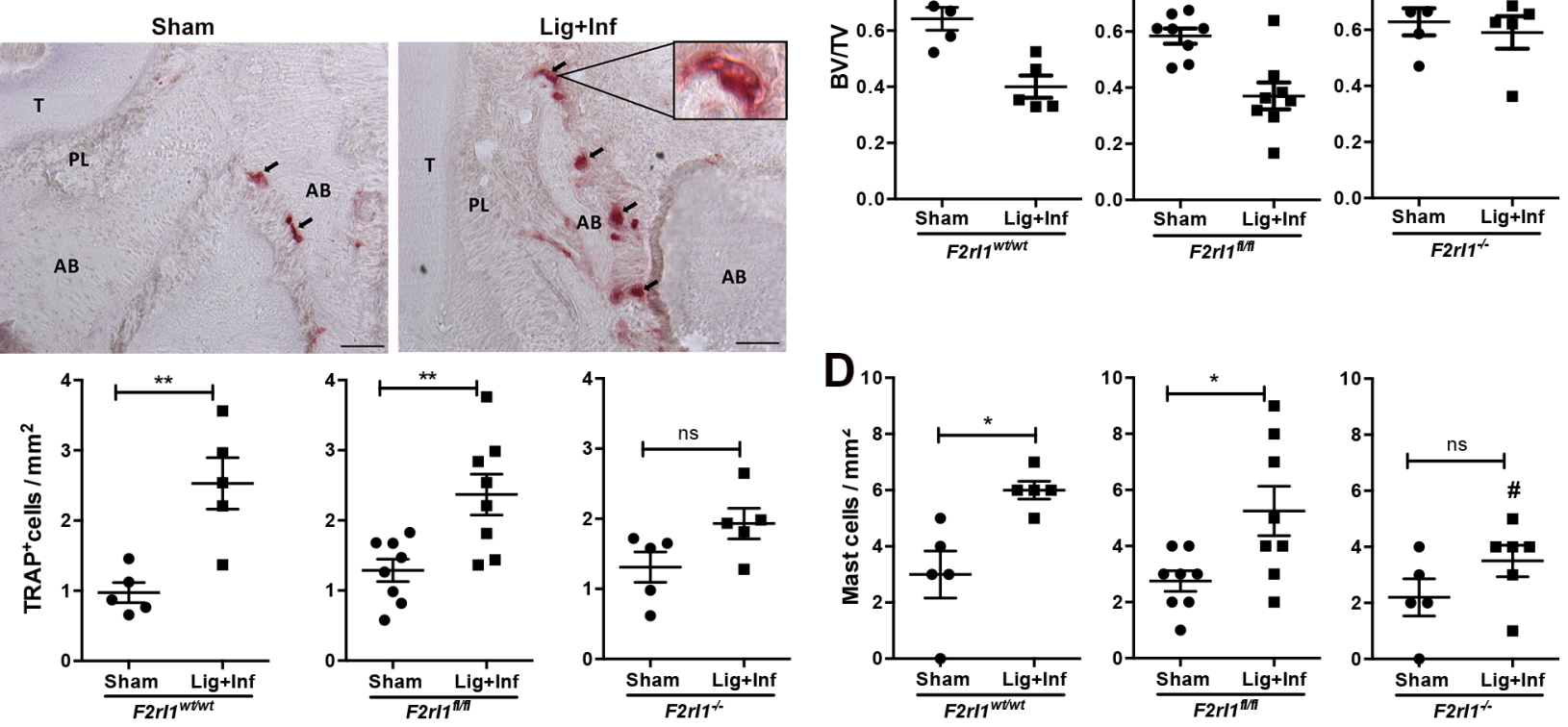

CMI_12891_F2.tif 

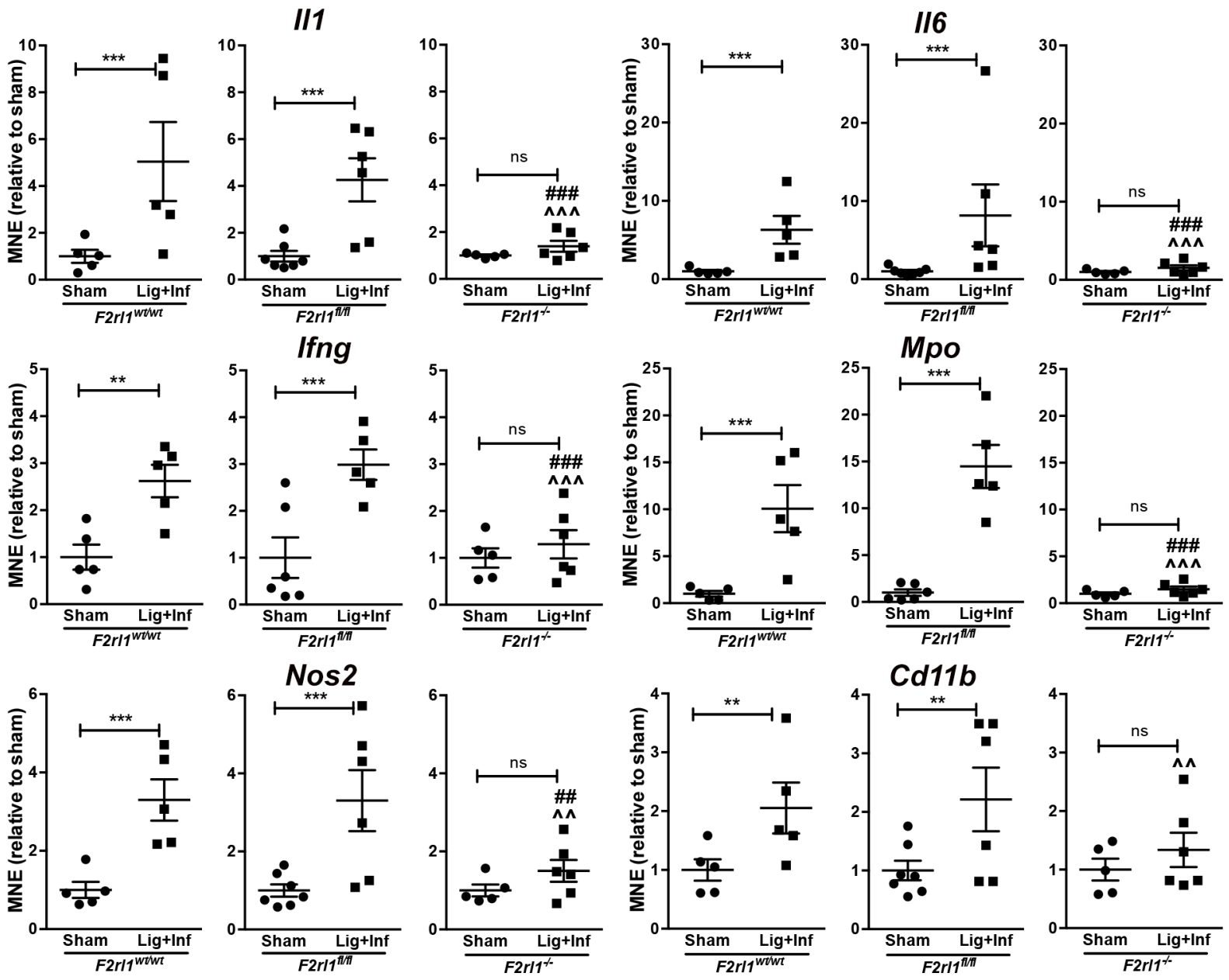

CMI_12891_F3.tif 


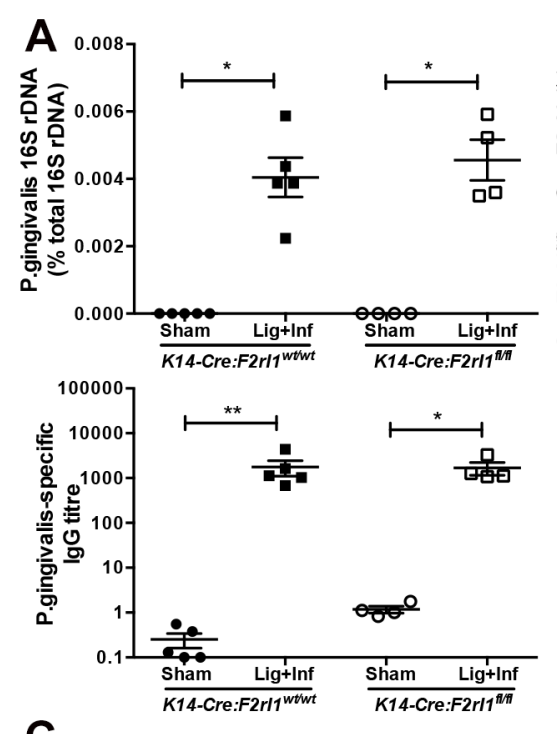

B sham
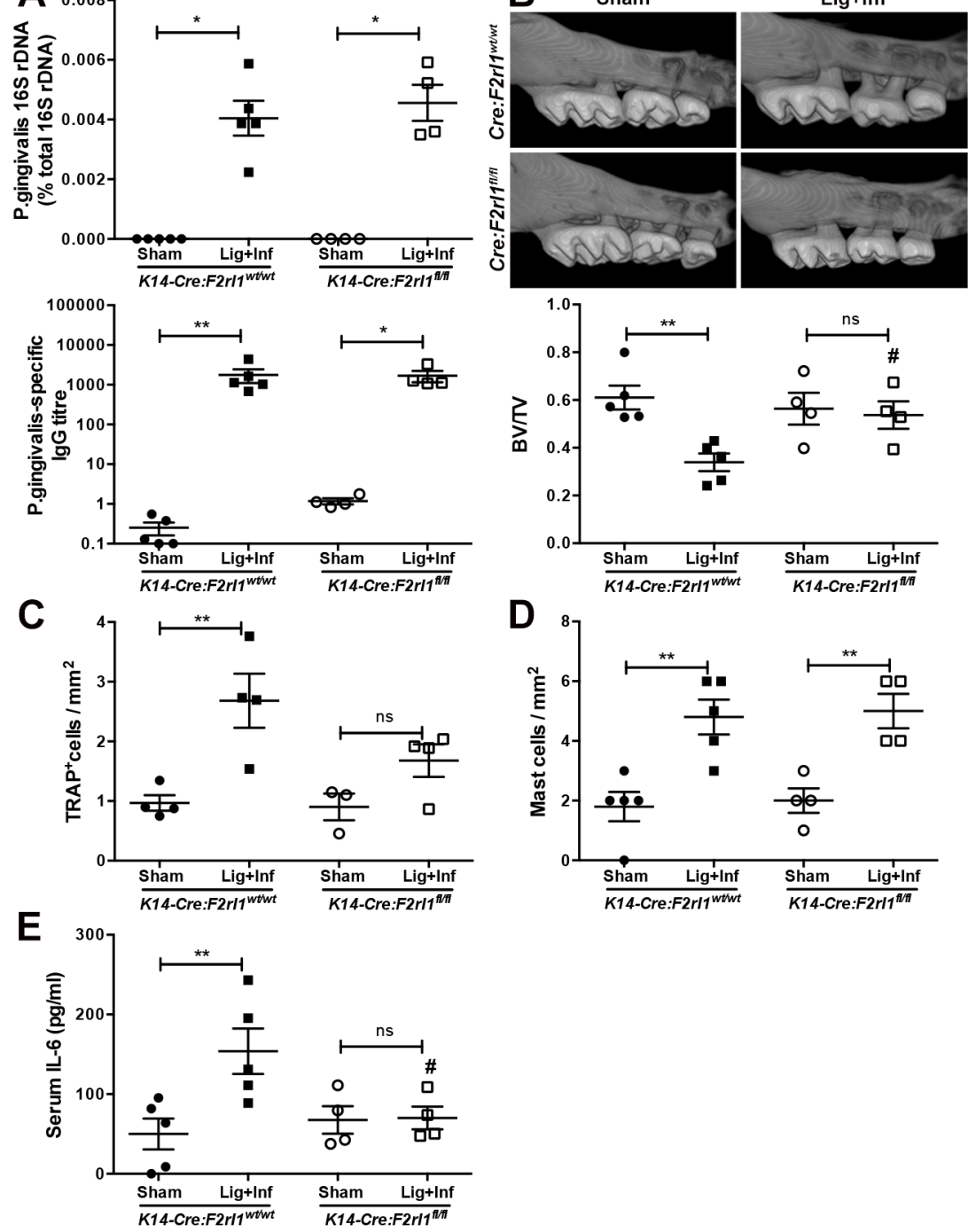

CMI_12891_F4.tif

This article is protected by copyright. All rights reserved. 

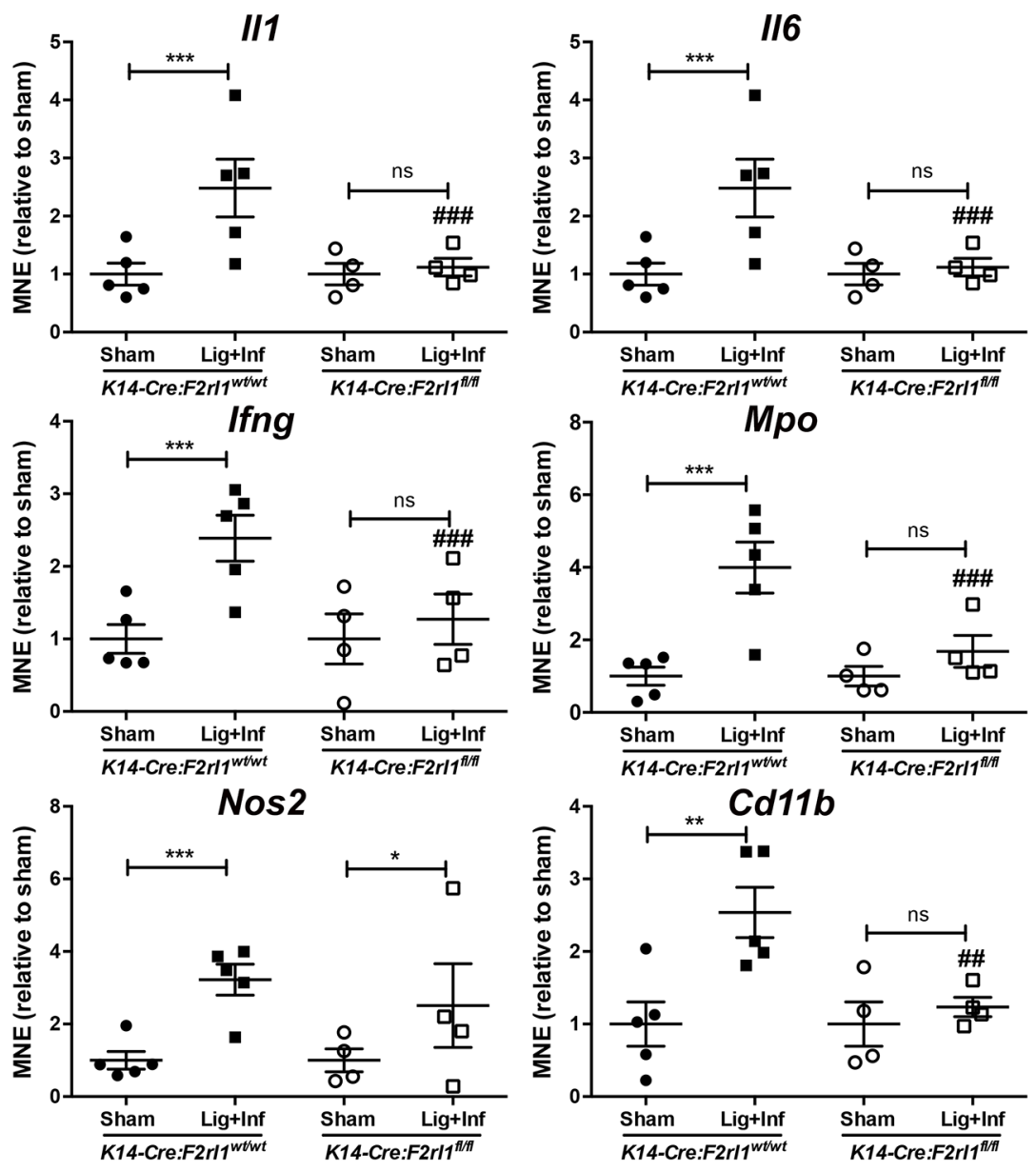

CMI_12891_F5.tif 


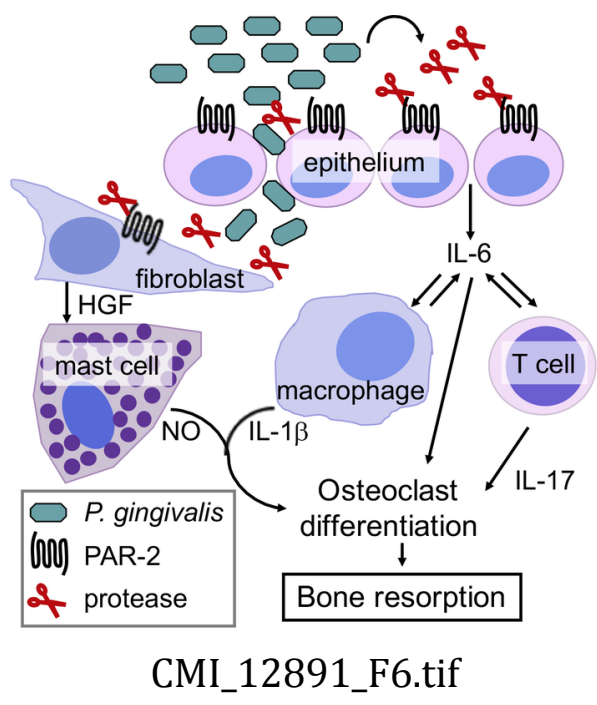

This article is protected by copyright. All rights reserved. 


\section{University Library}

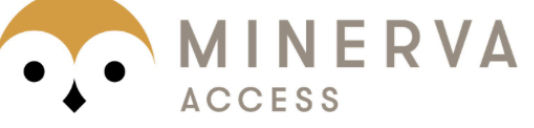

A gateway to Melbourne's research publications

Minerva Access is the Institutional Repository of The University of Melbourne

Author/s:

Francis, N;Ayodele, BA;O'Brien-Simpson, NM;Birchmeier, W;Pike, RN;Pagel, CN;Mackie, EJ

Title:

Keratinocyte-specific ablation of protease-activated receptor 2 prevents gingival inflammation and bone loss in a mouse model of periodontal disease

Date:

2018-11-01

\section{Citation:}

Francis, N., Ayodele, B. A., O'Brien-Simpson, N. M., Birchmeier, W., Pike, R. N., Pagel, C. N. \& Mackie, E. J. (2018). Keratinocyte-specific ablation of protease-activated receptor 2 prevents gingival inflammation and bone loss in a mouse model of periodontal disease. CELLULAR MICROBIOLOGY, 20 (11), https://doi.org/10.1111/cmi.12891.

Persistent Link:

http://hdl.handle.net/11343/284139 